\title{
The effect of the textural properties of bituminous coal chars on NO emissions
}

\author{
Ana Arenillas ${ }^{\mathrm{a}}$, Fernando Rubiera ${ }^{\mathrm{a}}$, José J. Pis ${ }^{\mathrm{a}^{*}}$, Jenny M. Jones ${ }^{\mathrm{b}}$ and Alan Williams ${ }^{\mathrm{b}}$ \\ a Instituto Nacional del Carbón, CSIC, Apartado 73, 33080 Oviedo, Spain \\ ${ }^{\mathrm{b}}$ Department of Fuel and Energy, The University of Leeds, Leeds, LS2 9JT, UK
}

\begin{abstract}
$\mathrm{NO}$ is the primary product of the oxidation of char nitrogen, and in some combustion processes the NO can be reduced on the char surface to give $\mathrm{N}_{2} \mathrm{O}$ and/or $\mathrm{N}_{2}$. In this study a range of bituminous coals (low, medium and high volatile matter content) were pyrolysed in a fixed bed reactor at various heating rates. Textural characterisation was carried out by measuring true $(\mathrm{He})$ and apparent $(\mathrm{Hg})$ densities and $\mathrm{N}_{2}\left(-196^{\circ} \mathrm{C}\right)$ and $\mathrm{CO}_{2}\left(0^{\circ} \mathrm{C}\right)$ adsorption isotherms. Pore volume distributions and surface areas were obtained for the chars studied. A thermogravimetric analyser coupled to a quadrupole mass spectrometer (TG-MS) was used to study the combustion behaviour of the samples and the nitrogen compounds evolved during temperature-programmed combustion. Results are discussed in terms of the influence of both textural properties and reactivity on NO emissions and on the heterogeneous reduction of NO.
\end{abstract}

(Keywords: char combustion, nitrogen oxides, texture)

\section{INTRODUCTION}

The current and expected future growth of coal consumption for energy generation is dependent on large, geographically, well-distributed reserves and on its comparatively low$\operatorname{cost}^{1}$. There is, however, serious concern about the environmental problems associated with the utilisation of coal as an energy source. Thus, in recent years, the environmental pressure to reduce pollutant emissions has led to more stringent legislation. The combustion of fossil fuels, such as coal, generates, among other pollutants, the nitrogen oxides, $\mathrm{NO}_{\mathrm{X}}$ (NO and $\mathrm{NO}_{2}$ ) and $\mathrm{N}_{2} \mathrm{O}$. Nitric oxide, $\mathrm{NO}$, contributes to photochemical smog and acid rain. Three major mechanisms for the formation of nitrogen oxides during coal combustion have been identified $^{2}$. Two of the routes involve the reaction of atmospheric nitrogen with oxygen, the Zeldovich mechanism, or via radical species such as $\mathrm{OH}$. The third route is the conversion of 
nitrogen chemically bound in the fuel. The reaction of atmospheric nitrogen is sensitive to temperature, and it is effectively controlled in modern coal combustion furnaces by staged combustion. Thus the nitrogen chemically bound in the parent coal is the main contributor to the nitric oxide emission during coal combustion.

The factors, which may affect emissions of nitrogen oxides during combustion, can be classified into combustion conditions and coal-related factors ${ }^{3}$. The first group includes combustor design and operating conditions, i.e. flame temperature, excess air, particle size, etc. Coal-related factors, which influence nitrogen oxides formation during combustion, include coal rank, char structure, char reactivity and total nitrogen content. Nitrogen functionalities in coals and their subsequent conversion to volatile nitrogen species and char nitrogen during the pre-combustion or pyrolysis stages are also relevant in the formation of nitrogen oxides.

Results reported in the literature ${ }^{4,5}$ suggest that nitrogen in coal is mostly contained in aromatic structures that decompose at high temperatures. In contrast, compounds lacking nitrogen, such as light hydrocarbons and carbon oxides, are evolved during the first stages of pyrolysis. As a consequence, the char is enriched in nitrogen. In previous work ${ }^{2}$ during the devolatilisation process approximately $70-90 \%$ of the nitrogen was retained in the char in the temperature range $700-1000^{\circ} \mathrm{C}$ under pyrolysis conditions, and this retention in the char was independent of coal rank. Recent advances in the design of combustors have led to an important decrease in the volatile nitrogen contribution to overall $\mathrm{NO}$ emissions. In low $\mathrm{NO}_{\mathrm{X}}$ burners and in fluidised bed coal combustion, char nitrogen has been identified as the main contributor to $\mathrm{NO}^{6,7}$. The evolution of char nitrogen and heterogeneous reduction is therefore a matter of concern. It is generally agreed that the heterogeneous reduction of $\mathrm{NO}_{\mathrm{X}}$ involves several stages ${ }^{8}$ : firstly chemisorption of the oxide, then the formation of surface complexes, and finally desorption and release of products. Nevertheless, several aspects of these reactions have still not been well defined. The nature of the active sites involved in the reduction is not well known. Some authors ${ }^{9}$ relate the active sites to free carbon sites, while others ${ }^{10}$ assign the active sites to oxygen surface groups on the carbonaceous material. It seems clear, however, that textural characteristics of the char can exert a strong influence on the overall heterogeneous reactions involved in the reduction of $\mathrm{NO}$ and $\mathrm{N}_{2} \mathrm{O}$. Char reactivity is an important factor in the conversion of fuel-N to NO since the rates of NO formation and destruction are strongly dependent on the intrinsic reactivity of char and its textural 
characteristics $^{11,12}$. The aim of this work was to study the effect of coal rank, textural properties and intrinsic reactivity of the chars, on NO emissions and on the heterogeneous reduction of $\mathrm{NO}$ over the char surface.

\section{EXPERIMENTAL}

Chars were prepared from the 0.5-1 mm size fraction of a series of bituminous coals (W, T and C). Ultimate and proximate analyses of these coals are shown in Table 1. Pyrolysis chars were obtained in an horizontal quartz reactor (i.d. $30 \mathrm{~mm}$ ), under nitrogen flow, up to a final temperature of $850^{\circ} \mathrm{C}$ and a soaking time of 1 hour. The coal $\mathrm{W}$ was pyrolysed at various heating rates $\left(5,50\right.$ and $\left.150^{\circ} \mathrm{C} / \mathrm{min}\right)$ in order to obtain chars with different textural properties. The resultant chars were denoted as W5, W50 and W150, respectively. The coals T and C were pyrolysed at $150^{\circ} \mathrm{C} / \mathrm{min}$ and the chars obtained were denoted as T150 and C150.

Textural characterisation of the chars was carried out by measuring true (helium) and apparent (mercury) densities. True densities were obtained in a pycnometer. Apparent densities were determined with mercury at $0.1 \mathrm{MPa} . \mathrm{N}_{2}\left(-196^{\circ} \mathrm{C}\right)$ and $\mathrm{CO}_{2}\left(0^{\circ} \mathrm{C}\right)$ gas adsorption isotherms were performed in an automated method. The Dubinin-Radushkevich method ${ }^{13}$ was used to calculate the micropore volume and the surface area of the samples studied. The distribution of small micropores $(<0.7 \mathrm{~nm})$, medium micropores $(0.7-2 \mathrm{~nm})$ and mesopores $(2-50 \mathrm{~nm})$ was obtained by application of the t-plot method to the $\mathrm{N}_{2}$ adsorption isotherms ${ }^{14}$. Active surface area values (ASA) were determined by a gravimetric method, described elsewhere ${ }^{15}$.

Isothermal gasification and temperature-programmed combustion (TPC) were determined in a differential thermogravimetric analyser (DTG). In order to compare the samples, factors such as sample weight, heating rate and gas flow rate were well established to ensure good repeatability between experimental runs. In all the experiments carried out in this work, approximately $25 \mathrm{mg}$ of sample ground to minus $0.212 \mathrm{~mm}$, a gas flow rate of $50 \mathrm{~mL} / \mathrm{min}$ and a linear heating rate of $15^{\circ} \mathrm{C} / \mathrm{min}$ were employed. The reactivities of the chars were evaluated in $20 \%$ oxygen in argon at $500^{\circ} \mathrm{C}$. Previously, the temperature was raised to $850^{\circ} \mathrm{C}$ in an argon flow to devolatilise the samples. After weight stabilisation, the temperature was lowered to $500^{\circ} \mathrm{C}$ before switching the flow to the reactive gas and the weight loss was monitored continuously. For the TPC experiments the temperature of the samples was raised to $1200^{\circ} \mathrm{C}$ in $20 \%$ oxygen in argon. 
A quadrupole mass spectrometer linked to the thermobalance was used to record the gas evolution profiles. To avoid secondary reactions a probe was placed very close to the sample crucible of the thermobalance, in the gas flow direction. A normalised procedure was applied to the signals given by the spectrometer to make the results internally consistent ${ }^{16}$. The MS intensity signal (A) was normalised to the maximum intensity of the experiment (A) and the initial sample mass $(\mathrm{g})$, the final units being obtained in the form of $(\mathrm{A} / \mathrm{Ag})$. In this way it was possible to compare the same $\mathrm{m} / \mathrm{z}$ signals for different samples. Species were monitored at $\mathrm{m} / \mathrm{z} 14\left(\mathrm{~N}_{2}^{++}\right), 27\left(\mathrm{HCN}^{+}\right), 28\left(\mathrm{~N}_{2}^{+}\right.$and $\left.{ }^{12} \mathrm{CO}^{+}\right), 29\left({ }^{13} \mathrm{CO}^{+}\right), 30\left(\mathrm{NO}^{+}\right.$and $\left.{ }^{12} \mathrm{C}^{18} \mathrm{O}^{+}\right), 44\left(\mathrm{CO}_{2}{ }^{+}\right)$ and $46\left(\mathrm{C}^{16} \mathrm{O}^{18} \mathrm{O}^{+}\right)$. The $\mathrm{N}_{2}^{++}$and $\mathrm{NO}^{+}$profiles were corrected for contributions from $\mathrm{CO}^{++}$ and ${ }^{12} \mathrm{C}^{18} \mathrm{O}^{+}$, respectively, using the method described by Jones et $\mathrm{al}^{17}$.

\section{RESULTS AND DISCUSSION}

\section{Influence of the heating rate}

Table 1 shows the proximate and ultimate analyses of the $\mathrm{W}$ chars obtained at different heating rates. This shows that the nitrogen is preferentially retained in the char. The nitrogen content of the chars is similar in all cases, irrespective of the pyrolysis conditions. In addition, the N/C atomic ratios are also similar for all the chars and the parent coal. It is well known that the residual volatile matter of the char depends on pyrolysis temperature. In this work different heating rates were used, performing all the pyrolysis experiments to the same final temperature, $850^{\circ} \mathrm{C}$. This could be the reason for the similar residual volatile matter and ultimate analysis values exhibited by all the chars, i.e. Table 1 . There is some difference in the ash content of the chars. Therefore the potential influence of the mineral matter in the combustion behaviour of the chars was also taken into account, as discussed later.

The heating rate used during the pyrolysis process exerted a marked effect on the texture of the resultant chars. As other researchers have found ${ }^{18}$, the heating rate markedly affects the yields of tar from coals. As the temperature rises, coal disproportionates into gases, liquids (including tar) and residual char. At high heating rates much of the tar escapes, unaltered, by evaporation whereas at slow rates much of the tar may disproportionate into gas and char rather than evaporate. Heating rate also influences the plastic behaviour of the sample ${ }^{19}$. An increase in the heating rate shifts the softening and resolidification points to higher temperatures. Since softening and resolidification temperatures do not increase to the same 
extent, there is usually a widening of the plastic range. As a consequence of the different behaviour during the plastic stage, different char structures were obtained between W5 and W150. Figure 1 shows SEM micrographs of the chars W5 and W150. The char W5 (Figure 1a) obtained at the lowest heating rate exhibits discrete near-spherical particles with few pores visible by SEM. The volatiles could not escape through the mass of char and as a result a hollow sphere (simple cenosphere) was formed. Remnants from the original coal edges can be observed on the left side of the photograph, confirming the low plasticity developed during the pyrolysis at $5^{\circ} \mathrm{C} / \mathrm{min}$.

At higher heating rates, i.e. $150^{\circ} \mathrm{C} / \mathrm{min}$, plastic properties are enhanced and the gases generated during pyrolysis produce an important internal pressure. This led to an unstable state since the plastic mass is not able to retain volatiles and they evolve from the particle producing tunnels and pores in the structure of the char as can be seen in Figure 1b. The pore size will depend on both the amount of volatile matter within the pores and the surface tension, which might be expected to decrease as the fluidity increases ${ }^{20}$. As a result significant differences in textural properties of the chars were obtained, as can be observed in Table 2. Both true and apparent densities increase with the heating rate used during char production. This could be caused by the loss of most of the volatiles present in the parent coal and crosslinking of the char structure. Surface area values calculated by $\mathrm{N}_{2}\left(-196^{\circ} \mathrm{C}\right)$ and $\mathrm{CO}_{2}$ $\left(0^{\circ} \mathrm{C}\right)$ gas adsorption, are also given in Table 2. As the heating rate increases both surface areas, measured by the two methods, also increase, although the $\mathrm{CO}_{2}$ surface areas are much greater than those of $\mathrm{N}_{2}$. This could be a consequence of the activated diffusion phenomenon into the internal pore structure of microporous carbonaceous materials ${ }^{21}$. Figure 2 shows the pore size distribution for the $\mathrm{W}$ chars obtained from the $t$ method applied to the $\mathrm{N}_{2}$ adsorption isotherms. Micropores are the main contributors to the surface area and mesopores are very important in reactants diffusion, thus they are often called feeder pores. As can be seen in Figure 2 the micropores, both small and medium, increase with the heating rate, giving as a result higher surface areas and more active sites. The determination of active surface area, ASA, gives an indication of the number of active sites. As can be seen in Table 2 the ASA values increase with an increase in the heating rate. In summary, an increase in the heating rate during pyrolysis, produced chars with higher micropore volume, surface area and ASA values. 
The different textural properties of the chars obtained at various heating rates will affect their reactivity towards oxygen and other gaseous reactants (e.g. NO). Figure 3 shows the evolution of chars conversion with time during isothermal gasification $\left(500^{\circ} \mathrm{C}\right)$ in $20 \mathrm{vol} . \%$ oxygen in argon. There is an increase in reactivity with the increase in the heating rate. This is shown by a faster conversion of the char W150 in comparison with those of the chars produced at lower heating rates, W50 and W5. As discussed above, higher heating rates produced chars with higher microporosity and ASA values. It seems clear that there is a connection between ASA and char reactivity since both parameters are affected by active sites concentration. The relation between ASA and reactivity will be discussed later.

Temperature-programmed combustion tests were also carried out on the $\mathrm{W}$ chars. The evolution of $\mathrm{CO}_{2}^{+}$and $\mathrm{NO}^{+}$for the chars $\mathrm{W} 5$ and $\mathrm{W} 150$ are presented in Figure 4, the evolution curves of the char W50 were intermediate between those of W5 and W150 chars, so its $\mathrm{CO}_{2}{ }^{+}$and $\mathrm{NO}^{+}$profiles have been omitted for clarity. The $\mathrm{CO}_{2}{ }^{+}$profiles are very similar (Figure 4a), but there is a slight shift in the $\mathrm{W} 150 \mathrm{CO}_{2}{ }^{+}$profile to a lower temperature, as a result of the higher reactivity (and ASA) of this sample. The $\mathrm{NO}^{+}$evolution profiles displays a bimodal peak in all samples (Figure $4 b$ ). This may indicate different sources of nitrogen in the char or the result of in-situ conversion of nitrogen functionality at temperatures above the HTT of the char. According to some authors ${ }^{22}$ pyrrolic nitrogen is the most abundant nitrogen functionality in coal, and the presence of pyridinic groups increases with rank. According to this, the first peak appearing at lower temperatures in the $\mathrm{NO}^{+}$profiles could belong to the pyrrolic nitrogen, and the second peak, appearing at approximately $1000^{\circ} \mathrm{C}$, could belong to pyridinic nitrogen. With reference to the above comments, it is noteworthy that an increase in the heating rate (W150) produced a corresponding increase in the pyridinic/pyrrolic ratio and the pyrrolic nitrogen appears in a lower proportion in the char W150 than in the char W5, Figure $4 b$.

Taking into account that the lower temperature peak is the main contributor to NO formation during combustion of all samples, the total NO peak area is bigger in W5 than in W150. The conversion of char nitrogen to NO can be calculated from these peak areas and are given in Table 1. As discussed previously, the conversion of char nitrogen to NO is dependent not only on char-N content, but also on the homogeneous ( $\mathrm{CO}+\mathrm{NO}$ reaction) and heterogeneous reduction of $\mathrm{NO}$ to $\mathrm{N}_{2}$ and $\mathrm{N}_{2} \mathrm{O}$. The results given in Figure 4 and Table 1 imply that the W150 char has more active sites available not only for reaction with oxygen but also in the 
heterogeneous NO reduction reactions. The consequence is that the global NO emission decreases as the heating rate used in char formation increases. The relation between nitrogen species evolution during the TPC experiments, reactivity and ASA values will be discussed later.

The potential influence of char mineral matter content on NO emissions was also studied. Mineral cluster dispersion was observed by SEM-EDAX showing no differences between the samples studied. TPC tests on demineralised samples obtained from chars W5 and W150 were also performed. The results reflected the same trend in that an increase in heating rate was accompanied by a corresponding increase in NO reduction. Thus, for these samples, the heterogeneous reduction of NO is independent of mineral matter content.

\section{$\underline{\text { Influence of coal rank }}$}

The series of bituminous coals were pyrolised under the same operating conditions, in order to examine the effect of coal rank on char combustion properties. Table 1 shows the analysis of the three coals used in this work and their respective chars obtained at $150^{\circ} \mathrm{C} / \mathrm{min}$. It can be observed that the residual volatile matter of the chars follows the trend $\mathrm{W} 150>\mathrm{T} 150>\mathrm{C} 150$, that corresponds to a decrease of rank in the parent coal. The ultimate analysis reveals that the nature of the chars differs slightly, the N/C atomic ratio follows the trend already mentioned. This is indicative of the presence of different functional groups composition in the coals.

According to the textural parameters presented in Table 3 the char C150 exhibits the highest micropore volume and surface area. The char T150, whose parent coal (T) is of intermediate rank between coals $\mathrm{W}$ and $\mathrm{C}$, also presents intermediate micropore volume and surface area values from $\mathrm{N}_{2}$ adsorption isotherms. But the $\mathrm{CO}_{2}$ adsorption, which is more commonly used to determine micropores, gives the lowest value of the char series for the micropore volume and surface area of the char T150. The pore size distribution, presented in Figure 5, shows that the char T150 posses an important proportion of mesopores, while in the chars W150 and $\mathrm{C} 150$, micropores (small and medium) are predominant. ASA values follow the trend $\mathrm{W}>\mathrm{T}$

$>\mathrm{C}$, and this means that the active sites increase as the rank of the parent coal decreases. Reactivity parameters obtained from isothermal gasification measurements at $500^{\circ} \mathrm{C}$ in $20 \%$ $\mathrm{O}_{2}$ in $\mathrm{Ar}$ (Table 4), reveal that $\mathrm{C} 150$ is the most reactive char possessing nearly twice the reactivity of $\mathrm{W} 150$, throughout the char conversion. Temperature-programmed combustion 
tests were also performed for this char series in order to study the evolution of the gaseous products. Figure 6 shows the $\mathrm{CO}_{2}{ }^{+}$evolution for the three chars studied. It can be observed that there is a shift of the profiles to lower temperatures and a narrowing of the combustion range as the rank of the parent coal decreases. The $\mathrm{NO}^{+}$evolution profiles, Figure 7 , show similar behaviour to those of $\mathrm{CO}_{2}{ }^{+}$, there is a shift in the higher temperature $\mathrm{NO}^{+}$peak to higher temperatures with an increase in the rank of the parent coal. The low temperature $\mathrm{NO}^{+}$ peak from W150 and C150 follow the same trend, but not that of T150, which appears at the lowest temperature. The variation in functional groups and texture could be the reason for this. The peak areas from the $\mathrm{NO}^{+}$evolution profiles give an indication of the $\mathrm{NO}$ emission during combustion. According to the results already discussed, lower NO emissions are expected for the char with higher textural development (i.e. micropore volume, surface area and ASA values) and higher reactivity in oxygen. In Table 1 the conversion of char nitrogen to NO are presented, and it seems clear that the chars with higher texture and reactivity present lower conversion of char nitrogen to NO.

In Figure 8 the relationships between reactivity in oxygen evaluated at $50 \%$ char conversion, nitrogen species production - $\mathrm{NO}^{+}(\mathrm{m} / \mathrm{z} 30), \mathrm{N}_{2}{ }^{2+}(\mathrm{m} / \mathrm{z} 14)$ - and ASA values are shown, for all the chars studied in this work (W5, W50, W150, T150 and C150). It should be noted that the species $\mathrm{N}_{2}{ }^{++}$could belong to $\mathrm{N}_{2}$ or $\mathrm{N}_{2} \mathrm{O}$, both nitrogen species are considered ${ }^{23}$ as the main products of the heterogeneous reduction of $\mathrm{NO}$ so it is better to refer to the species $\mathrm{N}_{2}{ }^{++}$ as a reduced species in general.

As it was mentioned before char reactivity increased with the heating rate used in char production and with the volatile matter content of the bituminous coals. It can be seen in Figure 8 that ASA values also increase with char reactivity. ASA and reactivity towards oxygen follow a linear trend $\left(\mathrm{R}^{2}=0.999\right)$ indicating that there are common concepts (i.e. active sites) involved in their evaluation. These sites are active not only towards oxygen but also towards other reactive gases like NO, thought to be the primary nitrogen compound formed during char combustion, which can be reduced via heterogeneous reduction reactions on the char surface. From Figure 8 it can be observed that as the reactivity in oxygen of the samples studied increases the NO emission decreases, indicating that heterogeneous reduction reactions are occurring. Moreover, the reduced species $\mathrm{N}_{2}{ }^{++}$was detected in greater proportion as the reactivity of the samples increase. According to the results obtained in this work, it seems that $\mathrm{N}_{2}^{++}$production follows the same trend as the ASA. For the sample W5, 
with negligible ASA value, the formation of the reduced species was also negligible implying that the heterogeneous reduction does not take place to an important extent. As ASA increases the reduced species emission also increases.

\section{CONCLUSIONS}

In this work the effect of varying bituminous coal char textural properties on NO emissions was studied by thermal analysis-mass spectrometry. It was found that an increase in the heating rate used during the pyrolysis step produced chars with higher textural properties (i.e. higher values of pore volume and total surface area). It was also observed that coal rank had a considerable influence on textural properties; coal chars produced under the same devolatilisation conditions gave higher active surface area values, as the rank of the parent coal decreased. For the chars obtained in this work, active surface area and char isothermal reactivity in oxygen followed a linear relationship. In addition, the results showed that chars with a higher amount of active sites (i.e. ASA values) were not only more reactive towards oxygen but also more active in the heterogeneous reduction of NO on the char surface. In short, the heating rate during the devolatilisation step and the rank of the parent coal had a clear influence on char texture and thus on the heterogeneous reduction of NO on the char surface.

\section{ACKNOWLEDGEMENTS}

Work carried out with a financial grant from the European Coal and Steel Community (ECSC Project 7220-ED/094)

\section{REFERENCES}

1 Song, C. and Schobert, H.H., Fuel, 1996, 71, 361.

2 Wang, W., Brown, S.D., Thomas, K.M. and Crelling J.C., Fuel, 1994, 73, 341.

3 Thomas, K.M., Fuel, 1997, 76, 457.

4 Pels, J.R., Wojtowicz, M.A. and Moulijn, J.A., Fuel, 1994, 73, 341.

5 Lázaro, M.J., Ibarra, J.V., Moliner, R., Gonzalez de Andrés, A. and Thomas, K.M., Fuel, 1996, 75, 1014.

6 Wang, W., Brown, S.D., Hindmarsh, C.J. and Thomas, K.M., Fuel, 1994, 73, 1381. 
7 Phong-Anant, D., Wibberley, L.J. and Wall, T.F., Combust. Flame, 1985, 62, 21.

8 Teng, H., Lin, H.C. and Hsieh, Y.S., Ind. Eng. Chem. Res., 1997, 36, 523.

9 Teng, H. Suuberg, E. and Calo, J.M., Energy \& Fuels, 1992, 6, 398.

10 Mochida, I., Ogaki, N., Fujitso, H., Komatsubara, Y. and Ida, S., Fuel, 1985, 64, 1054.

11 Shimizu, T., Sazawa, Y., Adschiri, T. and Furusawa, T., Fuel, 1992, 71, 361.

12 Wang, W.X., Thomas, K.M., Cai, H.Y., Dugwell, D.R. and Kandiyoti, R., Energy \& Fuels, 1996, 10, 409.

13 Dubinin, M.M., in Chemistry and Physics of Carbon, 1966, Ed. Walker Jr., P.L., Marcel Dekker, NY, USA.

14 Parra, J.B., Pis, J.J., de Sousa, J.C., Pajares, J.A. and Bansal, R.C., Carbon, 1996, 34, 783.

15 Rubiera, F., Arenillas, A., Parra, J.B. and Pis, J.J., ACS Div. Fuel Chem., 1998, 43, 1120 .

16 Arenillas, A., Rubiera, F. and Pis, J.J., J.Anal. Appl. Pyrol., in press.

17 Jones, J.M., Harding, A.W., Brown, S.D. and Thomas, K.M., Carbon, 1995, 33, 833.

18 Hamilton, L.H., Fuel, 1980, 59, 112.

19 Habermehl, D., Orywal, F. and Beyer, H.D., in Chemistry of Coal Utilization, 1981, Elliot, M.A., John Wiley and Sons, NY, USA.

20 Hays, D., Patrick, J.W. and Walker, A., Fuel, 1976, 55, 297.

21 Mahajan, O.P., Carbon, 1991, 29, 735.

22 Davidson, R.M., Nitrogen in coal, 1994, IEAPER/08, London, UK.

23 Jones, J.M., Ellyatt, W.A.T., Ndaji, F.E. and Thomas, K.M., Carbon, 1997, 35, 217. 
Table 1. Proximate and ultimate analyses of a series of bituminous coals and their chars.

\begin{tabular}{|c|c|c|c|c|c|c|c|c|c|}
\hline \multirow[b]{2}{*}{ Sample } & \multicolumn{2}{|c|}{$\begin{array}{l}\text { Proximate analysis } \\
(\mathrm{wt} \% \mathrm{db})\end{array}$} & \multicolumn{5}{|c|}{ Ultimate analysis (wt\% daf) } & \multirow{2}{*}{$\begin{array}{l}\mathrm{N} / \mathrm{C} \\
\text { atomic } \\
\text { ratio }\end{array}$} & \multirow{2}{*}{$\begin{array}{l}\mathrm{NO} / \mathrm{N} \\
\text { conversion }\end{array}$} \\
\hline & $\begin{array}{l}\text { Volatile } \\
\text { matter }\end{array}$ & Ash & $\mathrm{C}$ & $\mathrm{H}$ & $\mathrm{N}$ & $\mathrm{S}$ & $\mathrm{O}^{\mathrm{a}}$ & & \\
\hline $\mathrm{W}$ & 17.0 & 6.2 & 89.2 & 4.6 & 1.2 & 0.7 & 4.3 & 0.012 & 0.101 \\
\hline $\mathrm{T}$ & 25.1 & 6.8 & 88.8 & 5.0 & 1.6 & 1.2 & 3.4 & 0.015 & 0.103 \\
\hline $\mathrm{C}$ & 36.7 & 7.1 & 84.5 & 5.5 & 1.7 & 1.5 & 6.8 & 0.017 & 0.103 \\
\hline W5 & 1.9 & 6.3 & 96.0 & 0.9 & 1.5 & 0.5 & 1.1 & 0.013 & 0.063 \\
\hline W50 & 2.4 & 7.2 & 96.5 & 1.0 & 1.4 & 0.5 & 0.6 & 0.012 & 0.061 \\
\hline W150 & 1.7 & 8.0 & 95.8 & 0.9 & 1.4 & 0.5 & 1.4 & 0.013 & 0.059 \\
\hline $\mathrm{T} 150$ & 2.3 & 9.3 & 94.8 & 0.9 & 1.5 & 1.0 & 1.8 & 0.014 & 0.051 \\
\hline C150 & 3.5 & 9.8 & 93.8 & 0.9 & 2.1 & 1.2 & 2.0 & 0.019 & 0.050 \\
\hline
\end{tabular}

${ }^{\mathrm{a}}$ calculated by difference 
Table 2. Textural properties of the $\mathrm{W}$ chars.

\begin{tabular}{|c|c|c|c|c|c|c|c|}
\hline Sample & $\begin{array}{l}\text { True } \\
\text { density } \\
\left(\mathrm{g} / \mathrm{cm}^{3}\right)\end{array}$ & $\begin{array}{l}\text { Apparent } \\
\text { density } \\
\left(\mathrm{g} / \mathrm{cm}^{3}\right)\end{array}$ & $\begin{array}{l}\text { Surface } \\
\text { area }\left(\mathrm{N}_{2}\right) \\
\left(\mathrm{m}^{2} / \mathrm{g}\right)\end{array}$ & $\begin{array}{l}V_{\text {micro }} \\
\left(\mathrm{N}_{2}\right) \\
\left(\mathrm{mm}^{3} / \mathrm{g}\right)\end{array}$ & $\begin{array}{l}\text { Surface } \\
\text { area }\left(\mathrm{CO}_{2}\right) \\
\left(\mathrm{m}^{2} / \mathrm{g}\right)\end{array}$ & $\begin{array}{l}\mathrm{V}_{\text {micro }} \\
\left(\mathrm{CO}_{2}\right) \\
\left(\mathrm{mm}^{3} / \mathrm{g}\right)\end{array}$ & $\begin{array}{l}\text { ASA } \\
\left(\mathrm{m}^{2} / \mathrm{g}\right)\end{array}$ \\
\hline W5 & 1.77 & 0.95 & 1 & 0.4 & 75 & 28.7 & 0 \\
\hline W50 & 1.84 & 1.27 & 4 & 1.2 & 78 & 30.0 & 2 \\
\hline W150 & 1.92 & 1.35 & 7 & 2.4 & 143 & 54.6 & 8 \\
\hline
\end{tabular}


Table 3. Textural properties of a series of bituminous coal chars.

\begin{tabular}{|c|c|c|c|c|c|c|c|}
\hline Sample & $\begin{array}{l}\text { True } \\
\text { density } \\
\left(\mathrm{g} / \mathrm{cm}^{3}\right)\end{array}$ & $\begin{array}{l}\text { Apparent } \\
\text { density } \\
\left(\mathrm{g} / \mathrm{cm}^{3}\right)\end{array}$ & $\begin{array}{l}\text { Surface } \\
\text { area }\left(\mathrm{N}_{2}\right) \\
\left(\mathrm{m}^{2} / \mathrm{g}\right)\end{array}$ & $\begin{array}{l}V_{\text {micro }} \\
\left(\mathrm{N}_{2}\right) \\
\left(\mathrm{mm}^{3} / \mathrm{g}\right)\end{array}$ & $\begin{array}{l}\text { Surface } \\
\text { area }\left(\mathrm{CO}_{2}\right) \\
\left(\mathrm{m}^{2} / \mathrm{g}\right)\end{array}$ & $\begin{array}{l}\mathrm{V}_{\text {micro }} \\
\left(\mathrm{CO}_{2}\right) \\
\left(\mathrm{mm}^{3} / \mathrm{g}\right)\end{array}$ & $\begin{array}{l}\text { ASA } \\
\left(\mathrm{m}^{2} / \mathrm{g}\right)\end{array}$ \\
\hline W150 & 1.92 & 1.35 & 7 & 2.4 & 143 & 54.6 & 8 \\
\hline T150 & 1.87 & 1.26 & 9 & 3.1 & 135 & 51.5 & 14 \\
\hline $\mathrm{C} 150$ & 1.85 & 1.40 & 11 & 4.0 & 151 & 57.6 & 16 \\
\hline
\end{tabular}


Table 4. Reactivity parameters of a series of bituminous coal chars, determined at $500^{\circ} \mathrm{C}$ in $20 \% \mathrm{O}_{2}$ in $\mathrm{Ar}$.

\begin{tabular}{lllll}
\hline Sample & \multicolumn{3}{l}{ Reactivity $\left(\times 10^{4}\right)(\mathrm{mg} / \mathrm{mg} \mathrm{s})$} \\
\cline { 2 - 5 } & $\mathrm{X}=20 \%$ & $\mathrm{X}=40 \%$ & $\mathrm{X}=60 \%$ & $\mathrm{X}=80 \%$ \\
\hline $\mathrm{W} 150$ & 1.86 & 1.65 & 1.16 & 0.59 \\
$\mathrm{~T} 150$ & 2.96 & 2.46 & 1.73 & 0.84 \\
$\mathrm{C} 150$ & 3.47 & 2.89 & 1.99 & 1.11 \\
\hline
\end{tabular}



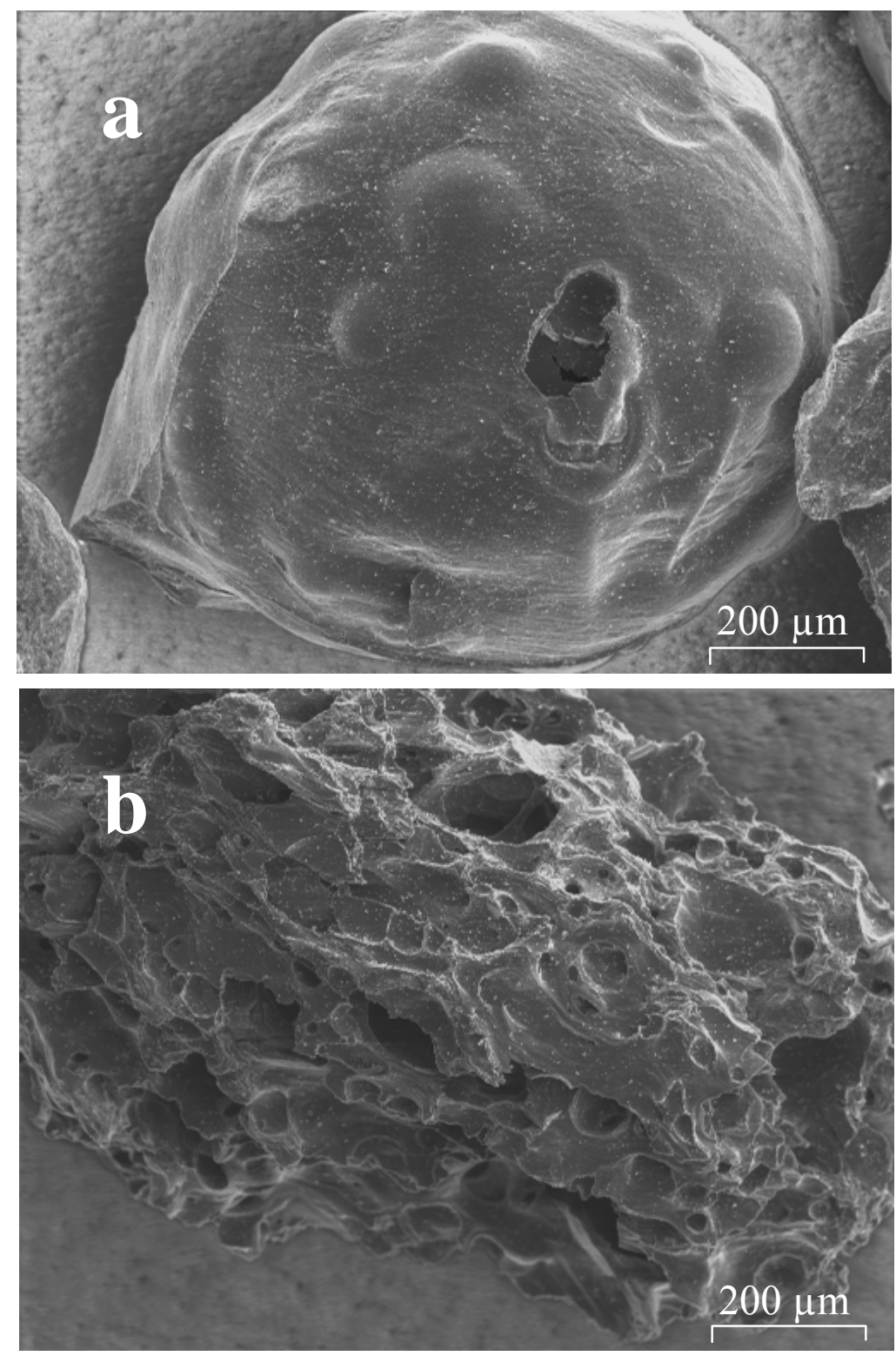

Figure 1. SEM micrographs of the chars obtained after pyrolysis of the $\mathrm{W}$ coal: (a) char W5; (b) char W 150. 


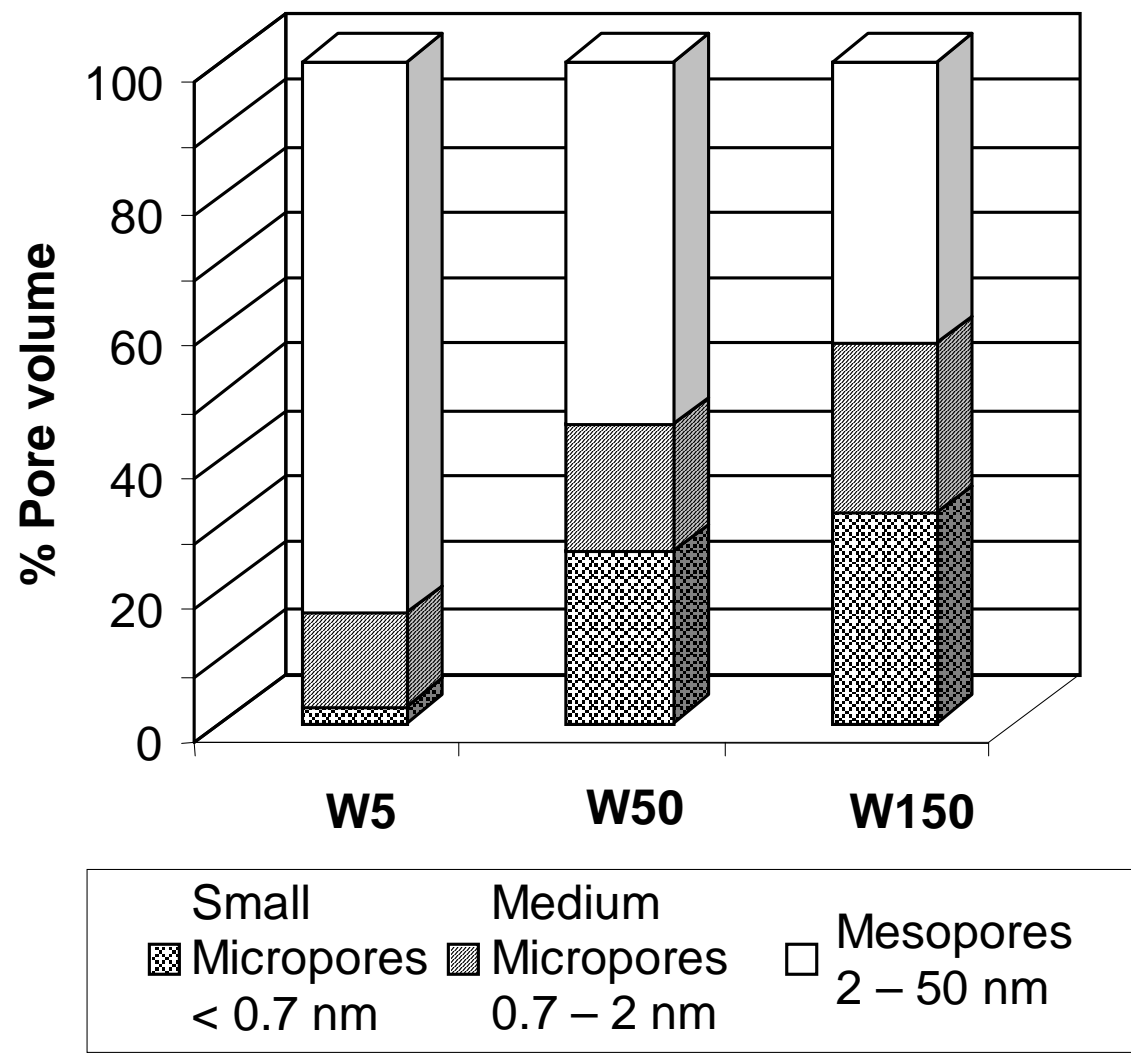

Figure 2. Pore volume distribution in the $\mathrm{W}$ chars. 


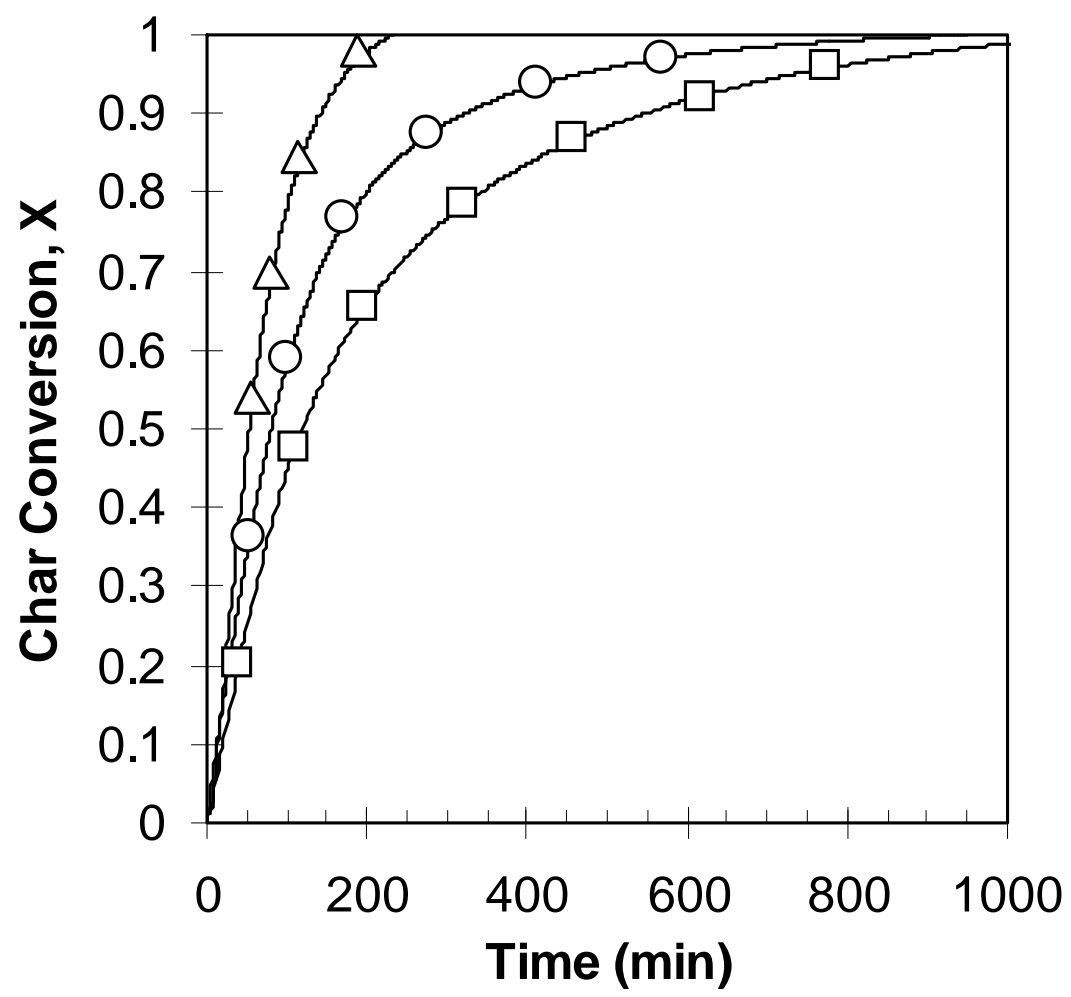

Figure 3. W chars conversion with time at $500{ }^{\circ} \mathrm{C}$ in $20 \% \mathrm{O} 2$ in $\operatorname{Ar}(\mathrm{W} \%$ : $\square$; W50: O; W150: $\Delta$ ). 

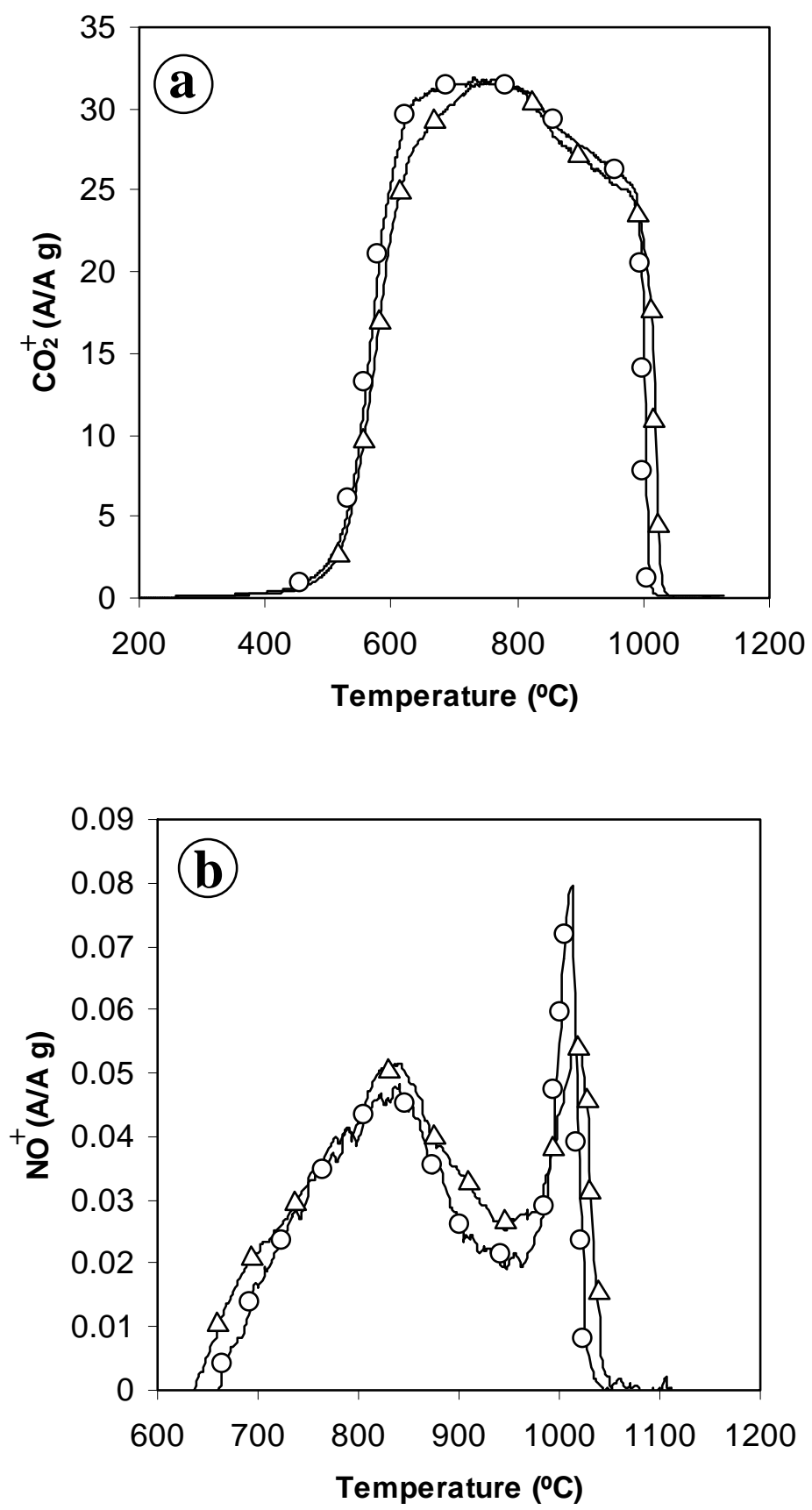

Figure 4. Evolution curves, for the $\mathrm{W}$ chars, followed by MS during temperature programmed combustion: (a) $\mathrm{CO}_{2}{ }^{+}$; (b) $\mathrm{NO}^{+}$(W5: $\Delta$; W150: O). 


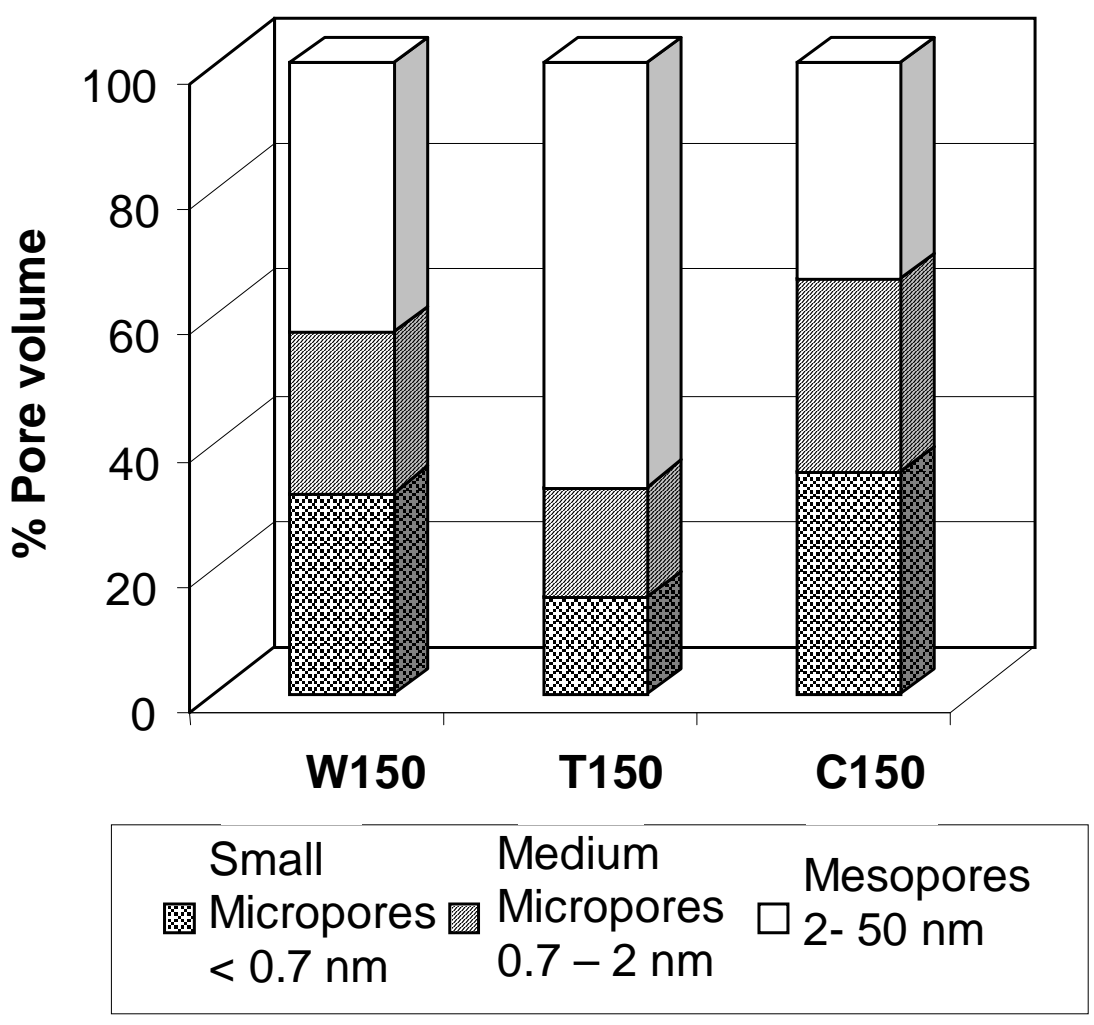

Figure 5. Pore volume distribution in the series of bituminous coal chars. 


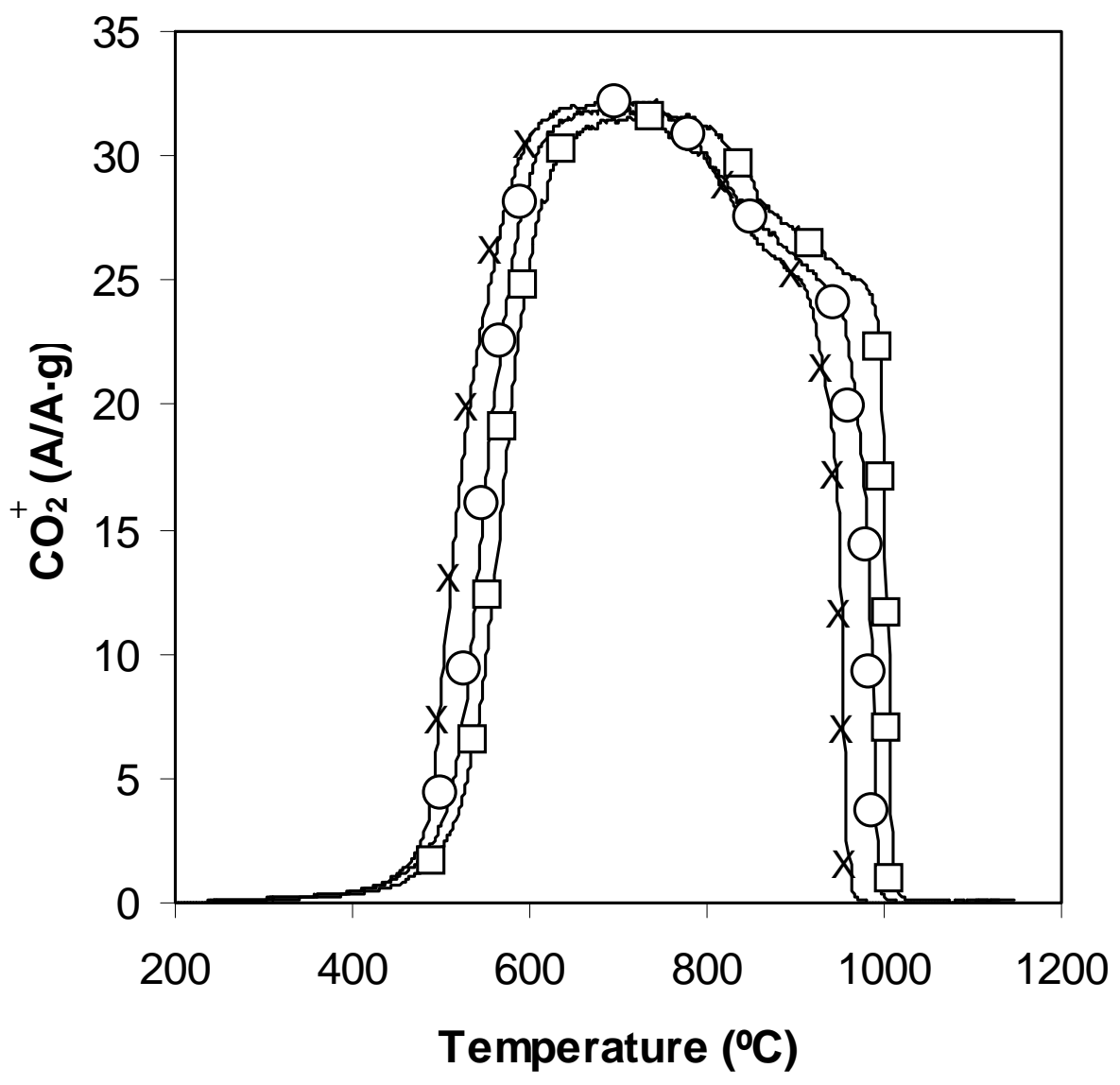

Figure 6. $\mathrm{CO}_{2}^{+}$evolution curves for the series of bituminous coals chars during temperatureprogrammed combustion (W150: $\square$; T150: O; C150: X). 


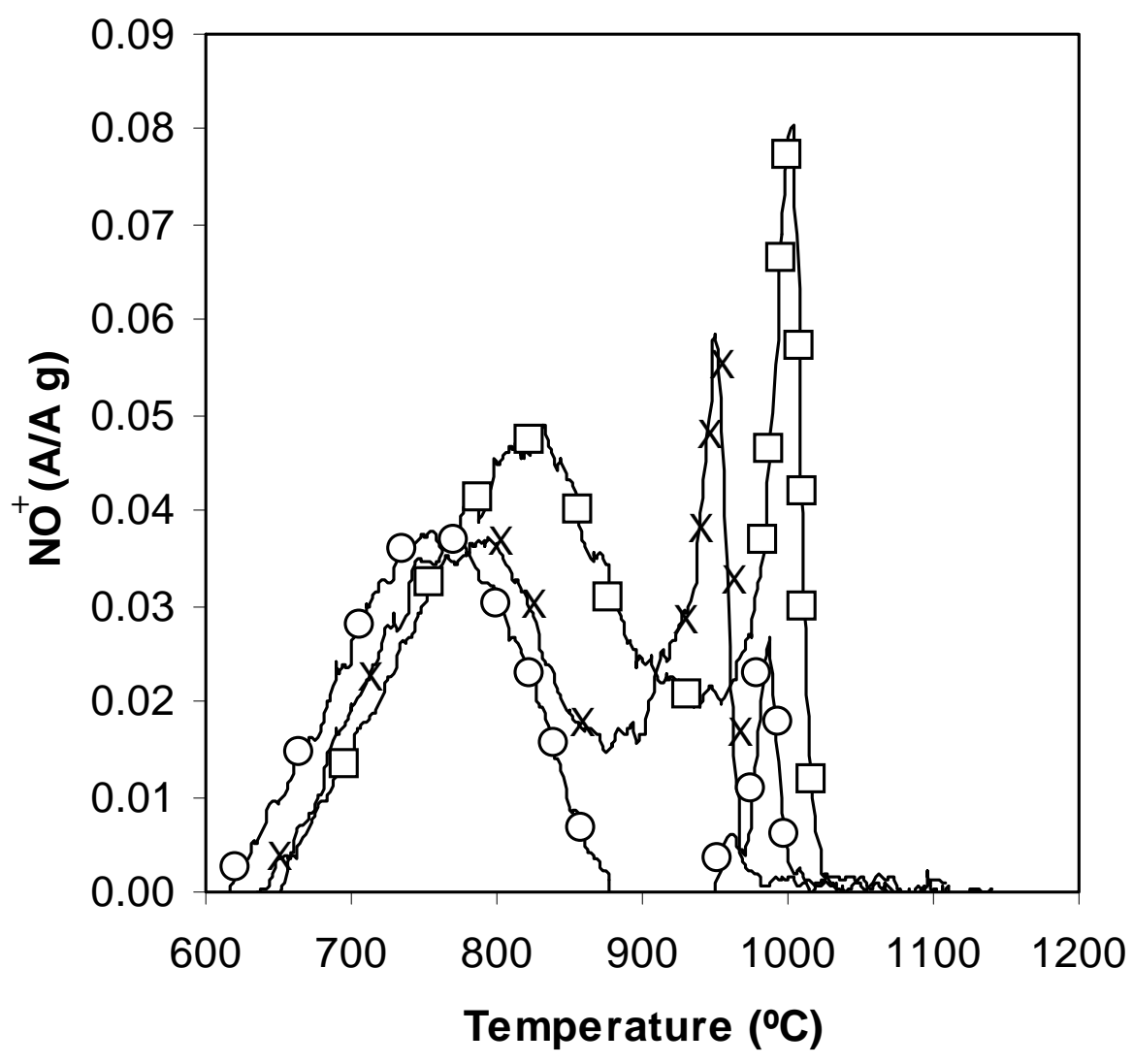

Figure 7. $\mathrm{NO}^{+}$evolution curves for the series of bituminous coals chars during temperatureprogrammed combustion (W150: $\square ; \mathrm{T} 150$ : $\mathrm{O} ; \mathrm{C} 150$ : X). 


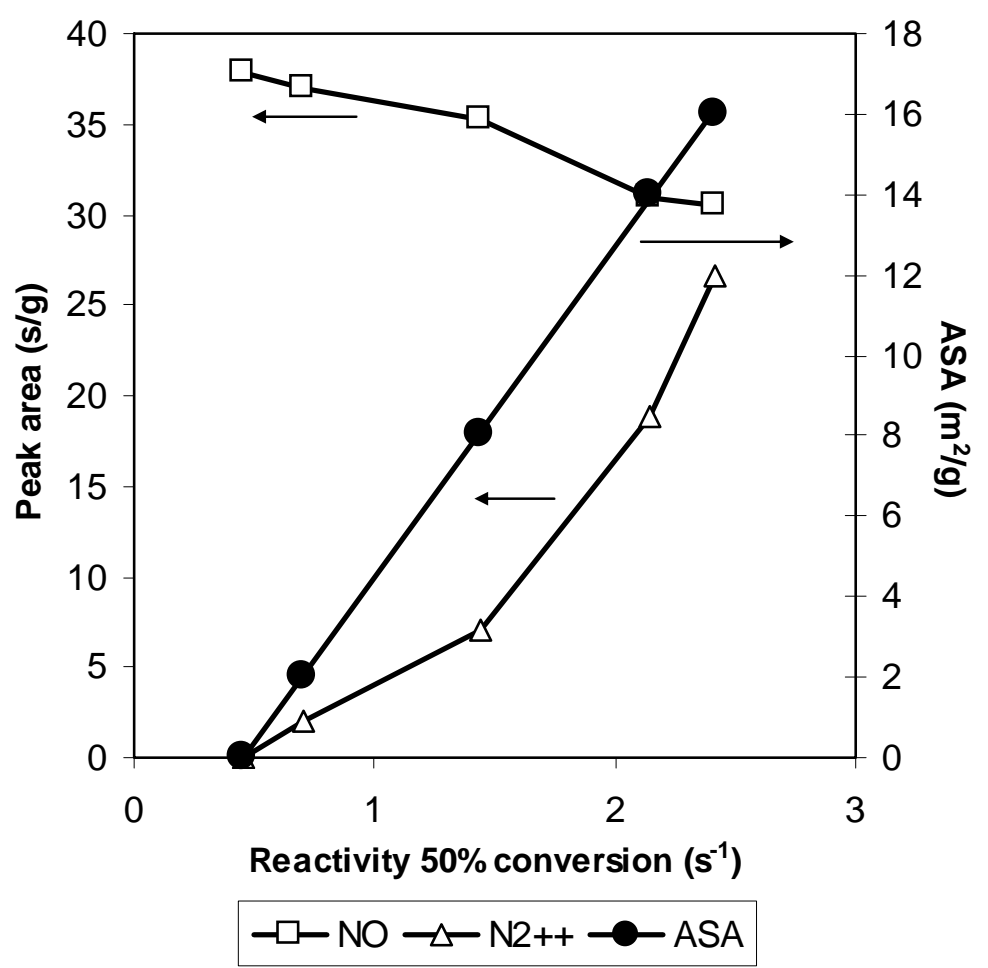

Figure 8. Relationship between char isothermal reactivity, ASA and nitrogen species emission during temperature-programmed combustion $\left(\mathrm{NO}^{+}: \square ; \mathrm{N}_{2}^{++}: \Delta\right.$; ASA: •). 